\title{
Kolon polipleri sayı ve büyüklüğü malignite göstergesi olabilir mi?
}

\author{
Can the number and size of colon polyps be indicative of malignancy?
}

Abdurahman ŞAHIN ${ }^{1}$, Nurettin TUNÇ${ }^{1}$, Salih KILIÇ ${ }^{1}$, Gökhan ARTAŞ², Ulvi DEMİREL ${ }^{1}$, Orhan K. POYRAZOĞLU ${ }^{1}$, Ibrahim H. BAHÇECIOĞLU ${ }^{1}$, Mehmet YALNIZ ${ }^{1}$

Fırat Üniversitesi Tıp Fakültesi, ${ }^{1}$ Iç Hastalıkları-Gastroenteroloji Bilim Dalı, ${ }^{2}$ Patoloji Ana Bilim Dalı, Elazı̆̆

Giriş ve Amaç: Önceden var olan kolorektal poliplerden, özellikle adenomlardan birkaç yıl sonra gelişen kolorektal karsinom gastrointestinal sistemin maligniteleri olup üçüncü en sık görülen kanserdir. Kolorektal karsinom insidans ve mortalitesi dünya çapında belirgin değişiklik göstermektedir. $\mathrm{Bu}$ coğrafi farklılık diyete, çevresel maruziyete ve genetik yatkınlığa bağlı gibi gözükmektedir. Bölgemizde kolorektal poliplerin histomorfolojik özelliklerinin değerlendirilmesi ve adenomatöz-nonadenomatöz poliplerin risk katmanlaşmasının belirlenmesi amaçlandı. Gereç ve Yöntem: Fırat Üniversitesi Tıp Fakültesi Gastroenteroloji Bilim Dalı'nda Haziran 2016-Aralık 2016 tarihleri arasinda 6 aylık bir periyotta kolonoskopi işlemi uygulanan toplam 827 kişiden kolonik polip saptanan 305 hastanın verileri retrospektif olarak incelendi. Hastalarin demografik verileri, patoloji ve kolonoskopi bulgular kaydedildi. Poliplerin özellikleri; kalın barsakta dağllımları, lokalizasyonu, büyüklükleri, sayısı, histolojik tipleri kaydedildi. Polip büyüklükleri $<5 \mathrm{~mm}$, 5-10 mm arası ve $>10 \mathrm{~mm}$ olmak üzere 3 gruba ayrıldı. Polip sayıları 5 'ten az, 5-10 arası ve 10'dan fazla olarak 3 sinifa ayrildı. Histoloji tipleri nonadenömatöz (hiperplastik), adenömatöz ve adenokarsinom olarak sinıfland1rıldı. Yüksek derecede displazi ve / veya invaziv kanser bulunan, boyu $1 \mathrm{~cm}$ veya daha büyük adenomlar, villöz histoloji olanlar ileri adenom (advanced adenom) olarak siniflandirildı. Bulgular: Toplam 827 hastaya kolonoskopi yapılmıs ve $305^{\prime}$ inde $(\% 36,9)$ polip saptanmıştı. Polip saptanan olgula-

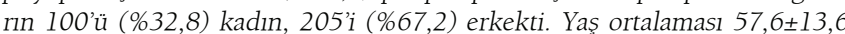
(min-max: 18-88) yıldı. Polip patolojik dağılımı 115'i $(\% 37,7)$ hiperplastik, 173 'ü $(\% 56,7)$ adenomatöz, 17'si $(\% 5,6)$ adenokarsinom olarak saptand. Adenömatöz poliplerin 106'sı (\%61,2) ileri adenom özellikteydi. Polipler hastaların 7l'inde $(\% 23,3)$ sağ kolon yerleşimli iken, 204'ünde $(\% 66,9)$ sol kolon, 30'unda $(\% 9,8)$ pankolonik yerleşimliydi. Adenomların çoğu (\%64) sol kolon yerleşimliydi ve tüm poliplerin $\% 27,9$, \%24,6 ve \%2,3'ü sirasıly tübüler, tübülovillöz, villöz adenomdu. Sonuç: Erkek cinsiyet, ileri yaș ve artan polip sayısı, ileri adenom ve adenokarsinom gelişimi ile ilişkili bulundu. Bu grup hastaların yakın takip ve izlemi gerekmektedir. Ülkemizde polip özelliklerinin belirlenmesi amaçh, geniş katılımlı çok merkezli prospektif çalıșmalara gereksinim vardır

Anahtar kelimeler: Polip, adenom, kolorektal karsinom
Background and Aims: Colorectal carcinoma is a gastrointestinal cancer that originates from colorectal polyps, particularly from adenomas, and it is the third most common cancer worldwide. The incidence and mortality rate of colorectal carcinoma markedly vary worldwide. These geographical differences may be related to dietary habits, environmental factors, and genetic susceptibility. In this study, the histomorphological features of colorectal polyps were evaluated in our region (Elazığ) and the risk stratification of adenomatous and nonadenomatous polyps was determined. Materials and Methods: Subjects who underwent colonoscopy during a 6-month period from June 2016 to December 2016 at the Gastroenterology Department of Firat University Hospital were retrospectively studied. Among 827 subjects, the data of 305 subjects who had colonic polyps were examined. Demographic features and colonoscopic and pathologic findings of the subjects were recorded. Polyp features including colonic distribution, localization, number, size, and histologic type were recorded. Polyps were divided into three subgroups based on their size as follows: $<5 \mathrm{~mm}$, between 5 and 10 $\mathrm{mm}$, and $>10 \mathrm{~mm}$. Polyps were further divided into three subgroups based on their number as follows: $<5$, from 5 to 10 , and $>10$ polyps. The histological types of polyps were classified as nonadenomatous (hyperplastic) adenomatous and adenocarcinoma. Polyps with a high degree of dysplasia and/ or invasive carcinoma, a size of $>10 \mathrm{~mm}$, and of the villous histological type were classified as advanced adenomas. Results: Among 827 subjects, 305 (36.9\%) had colonic polyps. Among these, 100 (32.8\%) were females and 205 (67.2\%) were males. Their mean age was $57.6 \pm 13.6$ years (min-max: 18-88). Based on the histological type, 115 subjects (37.7\%) had nonadenomatous polyps, 173 (56.7\%) had adenomatous polyps, and 17 (5.6\%) had adenocarcinomas. Among the 173 subjects with adenomatous polyps, 106 (61.2\%) had advanced adenomas. The polyps were pancolonic in 30 subjects (9.8\%) and located in the right colon in 71 subjects $(23,3 \%)$ and in the left colon in 204 subjects (66.9\%). Most of adenomas (64\%) were located in the left colon. Among all polyps, 27.9\%, 24.6\%, and 2.3\% were classified as tubular, tubulovillous, and villous adenomas, respectively. Conclusions: Male gender, advanced age, and increasing polyp number were found to be related to the development of advanced adenomas and adenocarcinomas. The close monitoring and follow-up of this group of patients are required. Prospective multicenter studies with a large number of patients are needed to determine the features of colonic polyps in Turkey.

Key words: Polyp, adenoma, colorectal carcinoma

gelişmekte olan ülkelerde özellikle Asya ve Afrika'da düşük oranlar vardır (5). Bu coğrafi farklılık diyete, çevresel maruziyete ve genetik yatkınlığa bağl gibi gözükmektedir (6). Ancak sosyo-ekonomik gelişme ve değişen yaşam tarzlarıyla KRK Asya ülkelerinde artmaktadır (7). Hindistan'da KRK için yaş standartlı insidans, 2008'de 4.3 iken 2012'de 100.000 erkek nüfusa 7.2'ye yükselmiştir (8).
Sahin A, Tunç N, Kilıç S, et al. Can the number and size of colon polyps be indicative of malignancy? Endoscopy Gastrointestinal 2017;25:14-18.
İletişim: Nurettin TUNÇ Fırat Üniversitesi Tıp Fakültesi, İç Hastalıkları Gastroenteroloji Bilim Dalı, Elazı ̆ Tel: +90 42423700 00/2414•E-mail: nurettin@ firat.edu.tr Geliş Tarihi: 10.04.2017 Kabul Tarihi: 15.04.2017 
Kolerektal karsinom (KRK) çok faktörlü bir hastalıktır. KRK'un çoğu (\%80) sporadik iken geri kalan tanımlanabilir genetik veya ailesel geçmişe sahiptir $(9,10)$. KRK'un, önceden var olan kolorektal poliplerden, özellikle adenomlardan, birkaç yll sonra geliştiği gösterilmiştir $(9,10)$. Adenomatöz poliplerin, düzensiz epitelyal proliferasyonu ve tam olgunlaşma veya farklılaşma gösterememesinden oluşan neoplazi (adenomatöz poliplerin karsinomaya dönüşümü) yaygın olarak araștırılan bir süreçtir ve genellikle adenoma-karsinom dizisi $(11,12)$ olarak bilinir. Büyüklük, adenom sayısı, histolojik tip ve displazi derecesi gibi çeşitli özellikler malign potansiyelin belirlenmesinde belirteçlerdir $(13,14)$.

Kolerektal karsinom (KRK) riski villöz/tübülovillöz polip (özellikle çok sayıda) öyküsü ve 1 cm'nin üzerinde adenomatöz polip varlığı ile artar (15). Çok sayıda izole, 1 cm'nin altında tübüler adenomun ise risk artışı yapmadığı bilinmektedir (15). Ailede 1 cm'nin üzerinde adenom veya villöz/tübülovillöz adenom öyküsü olması halinde, ailede KRK öyküsü olanlardaki gibi risk artışı olur (16). Sporadik KRK için yaş en büyük risk faktörüdür. 40 yaşın altında KRK nadirken, 40-50 yaştan sonra insidans artmaya başlamaktadır (4).

Kolorektal adenomlar için optimal tarama ile erken tespit ve adenomun çıkarılması KRK'a bağlı insidans ve mortalite oranını azaltabilir (17-19). Bu nedenle, adenomların erken dönemde saptanması ve çıkarılması KRK gelişimini ve insidansını azaltır (17-19). ABD National Polip Çalışması, referans popülasyona kıyasla kolonoskopi taraması yapılan hastalarda KRK görülme sıklığının çok düşük olduğunu göstermiştir (10). Batılı nüfusta, KRK prevalansının yüksek olması nedeniyle, kanser öncesi bir koşul olan adenomatöz polipin belirlenmesi kanser önlemeye yönelik temel adımdır.

Familyal adenomatozis polipozis koli (FAP) ve herediter non-polipozis kolorektal kanser (HNPCC) ailesel kolon kanserleri içinde en yaygın görülenler olmalarına karşılık, bunlar KRK vakalarının \%5’ten azını oluşturur (20).

Bu çalışmada bölgemizde kolorektal poliplerin histomorfolojik özelliklerinin değerlendirilmesi ve adenomatöz-nonadenomatöz poliplerin risk katmanlaşmasının belirlenmesi amaçlandı.

\section{GEREÇ ve YÖNTEM}

Bu çalışmada Fırat Üniversitesi Tıp Fakültesi Gastroenteroloji Bilim Dalı'nda Haziran 2016-Aralık 2016 tarihleri arasında 6 aylık bir periyotta kolonoskopi işlemi uygulanan toplam 827 kişiden kolonik polip saptanan 305 hastanın verileri retrospektif olarak incelendi. Hastane kayıt sisteminden hastaların yaş, cinsiyet, laboratuvar, patoloji, kolonoskopi bulguları sorgulandı. Poliplerin özellikleri; kalın barsakta dağılımları, lokalizasyonu, büyüklükleri, sayısı, histolojik tipleri kaydedildi. Poliplerin anatomik dağılımları; rektum, sigmoid, inen kolon, transvers kolon, çıkan kolon ve çekum, sol kolon (splenik fleksura distali), sağ kolon (splenik fleksura proksimali), pankolonik (hem sağ hem sol kolonda lokalize ise) olarak sinıflandırıldı. Birden çok sayıda polip saptananlarda biyopsi en büyük polipten alındı ve polip büyüklügü biyopsi forsepsi açık iken genişliğine göre hesaplandı. Polipler büyüklükleri 5 mm'den küçük, 5-10 mm arası ve 10 mm'den büyük olmak üzere 3 gruba ayrıldı. Polip saylları 5'ten az, 5-10 arası ve 10'dan fazla olarak 3 sinıfa ayrildı. Histoloji tipleri nonadenömatöz (hiperplastik), adenömatöz (tübüler, tübülovillöz, villöz) ve adenokarsinom olarak sinıflandırıldı. Poliplerin histolojisi ve boyutları patoloji kayıtlarından elde edildi. Yüksek derecede displazi ve/veya invaziv kanser bulunan, boyu $1 \mathrm{~cm}$ veya daha büyük adenomlar, villöz histoloji olanlar ileri adenom (advanced adenom) olarak sinıflandırıldı (22). Tüm kolon segmentlerinde farklı boyut ve lokalizasyonda toplam 10'dan fazla sayıda adenomatöz polip saptanması polipozis koli, familiyal adenamatöz polipozis (FAP) sendromu ise buna ek olarak ailede polipozis koli veya erken yaşta kolorektal kanser olması olarak tanımland.. Inflamatuvar barsak hastalığının neden olduğu inflamatuvar psödopolipler, infeksiyöz etyolojiye sekonder polipler ve çalışmada verilerine tam ulaşılamayan hastalar çalışmadan çıkartıldı.

\section{İstatistik}

Tüm veriler istatiksel analizi SPSS 22.00 paket programı kullanılarak yapıldı. Sonuçlar kategorik değişkenler için yüzde, sürekli değişkenler için ortalama \pm standart sapma veya ortanca (25 persentil - 75 persentil) olarak sunuldu. Grup oranlarının karşılaştırılmasında ki kare ve Fisher's exact test kullanıldı. Grup ortalamalarının karşılaştırılmasında normal dağılım gösteren değişkenler için Student t testi, normal dağllım göstermeyen değişkenler için Mann-Whitney U ile Wilcoxon işaret testleri kullanıldı. Ikiden fazla grupta degişkenlerin ortalamaları karşlaştırılırken parametrik değişkenlerde ANOVA yöntemi, nonparametrik değişkenlerde Kruskal Wallis testi kullanıldı.

\section{BULGULAR}

Toplam 827 hastaya kolonoskopi yapılmıs ve 305'inde $(\% 36,9)$ polip saptanmıştı. Polip saptanan olguların 100'ü $(\% 32,8)$ kadın, 205’i $(\% 67,2)$ erkekti. Yaş ortalaması 57,6 $\pm 13,6$ (minimum-maksimum: 18-88) yldı. Yapilan histopatolojik değerlendirmede hastaların 115'i $(\% 37,7)$ hiperplastik, 173'ü $(\% 56,7)$ adenomatöz ve 17'si $(\% 5,6)$ adenokarsinom olarak saptand. Adenömatöz poliplerin 106'sı $(\% 61,2)$ ileri adenom özellikteydi (Tablo 1). Ortanca (\%25$\% 75)$ hiperplastik polip sayısı 1 (1-2) idi. Ortanca (\%25-75) adenomatöz polip sayısı 2 (1-3) bulundu ( $\mathrm{p}=0,001)$.

İki yüz elli bir $(\% 82,3)$ hastada 4'ten az, 14'ünde $(\% 4,6)$ 5-10 adet arasinda, 40'inda $(\% 13,1) 10$ 'dan fazla polip saptand.. Polipler 40 yaş altında $43(\% 14,1)$ hastada, $40-60$ yaş grubunda $136(\% 44,6), 60$ yaş üstünde $126(\% 41,3)$ hastada saptandı. 
Tablo 1. Polip saptanan olguların demografik, klinik ve endoskopik özellikleri

\begin{tabular}{|c|c|}
\hline Klinik özellikleri & N (\%) \\
\hline \multicolumn{2}{|l|}{ Yaş } \\
\hline Ortalama yaş, yll (ort $\pm S S$ ) & $57,6 \pm 13,6$ \\
\hline$<40$ & $43(14,1)$ \\
\hline $40-60$ & $136(44,6)$ \\
\hline$>60$ & $126(41,3)$ \\
\hline \multicolumn{2}{|l|}{ Cinsiyet } \\
\hline Kadın & $100(32,8)$ \\
\hline Erkek & $205(67,2)$ \\
\hline \multicolumn{2}{|l|}{ Lokalizasyon } \\
\hline Sağ kolon & $71(23,3)$ \\
\hline Sol kolon & $204(66,9)$ \\
\hline Pankolonik & $30(9,8)$ \\
\hline \multicolumn{2}{|l|}{ Patoloji } \\
\hline Hiperplastik & $115(37,7)$ \\
\hline Adenomatöz & $173(56,7)$ \\
\hline Tübüler & $85(49,1)$ \\
\hline Tübülovillöz & $75(43,4)$ \\
\hline Villöz & $7(4,0)$ \\
\hline Mikst & $6(3,5)$ \\
\hline Adenokarsinom & $17(5,6)$ \\
\hline Rektum & $10(58,8)$ \\
\hline Sigmoid kolon & $5(29,4)$ \\
\hline Inen kolon & $1(5,8)$ \\
\hline Çıkan kolon & $1(5,8)$ \\
\hline \multicolumn{2}{|l|}{ Polip sayısı } \\
\hline$<5$ adet & $251(82,3)$ \\
\hline 5-10 adet & $14(4,6)$ \\
\hline$>10$ adet & $40(13,1)$ \\
\hline
\end{tabular}

Polipler yaş ilerledikçe erkeklerde daha sik saptanmasına ră̆men istatistiksel anlamlı değildi $(\mathrm{p}=0,714)$. Polip lokalizasyonu hastaların 7l'inde $(\% 23,3)$ sağ kolon, 204'ünde $(\% 66,9)$ sol kolon, 30'unda $(\% 9,8)$ pankolonik yerleşimliydi (Tablo 1).

Nonadenomatöz (hiperplastik polip) 115 (\%37,7) hastada saptandı. Ortalama yaş 56,6 yl olup \%7l'i erkekti. Poliplerin $\% 66,9$ 'u sol kolonda (12 adet polip inen kolonda, 65 adet rektosigmoid kolon) saptandı. Polip sayısı çoğunda $(\% 90,4)$ 5'in altında, polip boyutları \%50,4'ünde 5 mm'den küçüktü. Adenomatöz polip, $173(\% 56,7)$ hastada saptand. Ortalama yaş 58,3 yıldı ve 6l'i $(\% 35,3)$ kadın, 112'si $(\% 64,7)$ erkekti. Adenomların çoğu (\%64) sol kolon yerleşimliydi. Tüm polipler göz önüne alınarak yapılan değerlendirmede, tüm poliplerin \%27,9'u tübüler adenom, \%24,6'sı tübülovillöz ve \%2,6's1 villöz adenom özelliği göstermekteydi (Tablo 1, 2). Ileri adenom, adenomatöz poliplerin 106'sinda $(\% 61,2)$ saptandi. Yaş ortalaması 58 yıl olup, çoğu (\%46) 60 yaş üstünde, 38'i (\%35,8) kadın, 68'i $(\% 64,2)$ erkekti. Pankolonik adenomu olanların büyük çoğunluğu $(\% 53,3)$ ileri adenomdu.

Hiperplastik polipler adenomatöz poliplerle karşılaştırıldığında daha az sayıda (5 mm küçük olma sirasıyla \%91,3'e \%79, p: <0,001) ve daha küçük boyutlarda (sırasıyla \%50,4'e karşı $\% 14,6, p=0,001$ ) olma eğilimindeydi. Hiperplastik poliplerle karşılaştırıldığında adenomatöz poliplerde pankolonik tutulum (sırasıly \%3,4'e karşı \% 13,3, p= 0,009), poliplerin 10 mm'den büyük olması (\%7,8'e $\% 36, \mathrm{p}: 0,000)$, polip sayısının 10'un üzerinde olması (sirasiyla \%4,3'e \% 16,2, p:<0,001) anlamlı olarak daha sık görülmekteydi.

Adenokarsinom $17(\% 5,6)$ hastada saptand ve kolonoskopi yapılan tüm hastaların (17/827) \%2,05'ini oluşturmaktaydı. Adenokarsinomlarda ortalama polip sayısı 25 adet ve ortalama polip büyüklügü $24 \mathrm{~mm}$ olarak saptandı. Bu hastaların 10'u $(\% 58,8)$ rektum, 5'i $(\% 29,4)$ sigmoid kolon, 1'i $(\% 5,8)$ çıkan kolon, l'i $(\% 5,8)$ inen kolonda saptanmıştı. 11'i $(\% 64,7)$ erkek 6'sı $(\% 35,3)$ kadindı. Adenokarsinomlularda ortalama yaş 60,3 yıldı. Hastaların 7'si 40-60 yaş arasında, 8'i 60 yaş üstü hastalarda görüldü (Tablo.1).

Tablo 2. Histopatolojik tiplere göre grupların özellikleri

\begin{tabular}{|c|c|c|c|c|}
\hline & Hiperplastik & Adenomatöz & İleri Adenom & Adenokarsinom \\
\hline Yaş, yll (ortalama $\pm S S)$ & $56,6 \pm 13,7$ & $58,3 \pm 13,2$ & $58,8 \pm 13,3$ & $60,35 \pm 16,4$ \\
\hline Büyüklük, mm (ortalama $\pm S S)$ & $6,1 \pm 5,3$ & $12,24 \pm 10,5$ & $20,52 \pm 12,8$ & $24,12 \pm 19,3$ \\
\hline Sayı (ortalama \pm SS) & $2,75 \pm 6,79$ & $9,95 \pm 19,3$ & $13 \pm 24,4$ & $25,06 \pm 34,8$ \\
\hline $\begin{array}{l}\text { Lokalizasyon n (\%) } \\
\text { Rektosigmoid } \\
\text { Inen kolon } \\
\text { Transvers kolon } \\
\text { Çekum-çıkan kolon } \\
\text { Pankolonik }\end{array}$ & $\begin{array}{c}65(56,5) \\
12(10,4) \\
16(13,9) \\
18(15,6) \\
4(3,4)\end{array}$ & $\begin{array}{l}64(37,0) \\
34(19,7) \\
22(12,7) \\
31(17,9) \\
22(12,7)\end{array}$ & $\begin{array}{c}46(43,3) \\
20(18,8) \\
11(10,3) \\
13(12,2) \\
16(15)\end{array}$ & $\begin{array}{c}13(76,4) \\
1(5,8) \\
0 \\
0 \\
3(17,6)\end{array}$ \\
\hline
\end{tabular}




\section{TARTISSMA}

Kolorektal karsinomların (KRK) çoğunun önceden var olan adenomdan ortaya çıktığı iyi bilinmektedir $(14,15)$. Adenomatöz polipin saptanması, KRK progresyonunun önlenmesinde önemli bir adımdır. Adenom tespit oranı, incelenen popülasyona göre değişir. Batı ülkelerinde Asya'dan daha yüksek oranlarda adenom saptanmaktadır (22). Kolorektal adenomlar için optimal tarama asemptomatik olsalar bile önemlidir. Erken tespit ve adenomun çıkarılması KRK insidansı ve mortalite oranını azaltabilir (17-19).

Çalışmamızda kolonoskopi uygulanan vakaların (305/827) \%36,8'inde polip saptanmış bu oran 1899 vaka ile yapılan Tayvan'lliarda (23) \%27,4 ve Hispanik'lerde (24) saptanan \%30 polip oranından daha yüksekti. Bu durum bölgemizde genetik ve çevresel etkiler ile ya da kullanılan kolonoskopik cihazlarda teknolojinin tanı koyma oranlarını arttırmasıyla açılanabilir. Bu nedenle daha yakın takip ve daha erken yaşlarda tarama programları yapılmalıdır. Ortalama yaş Tayvan (23) ve Hispanik'lerde (24) olduğu gibi çoğunlukla 50 üstüydü.

Çalışmamızda erkek cinsiyette HP, adenomatöz, adenokarsinom daha fazla görülmesi Laird-Fick ve arkadaşlarının (25) 50 yaş üstü popülasyonun incelendiği çalışmayla benzerdi. Polipler yaş ilerledikçe erkeklerde daha sık saptanmaktaydı.

Çalışmamızda tüm polip türleri sol kolonda daha sık görülmekteydi, Laird-Fick ve arkadaşlarının (25) 50 yaş üstü hastaların araştırıldığı çalışmasında vakaların \%50'den fazlasının sağ kolonda görülmesinin aksine hastalarımızın çoğuna sigmoidoskopi ile tanı konulabilir.

Hiperplastik poliplerin çoğu Hispaniklerde (24) yapılan çalışmayla benzer olarak daha çok sol kolon (özellikle rektosigmoid bölgede) tutulumlu, boyutları daha küçük ve daha az sayıda olma eğilimindeydiler. Nonneoplastik olan hiperplasik polipler daha az sayıda ve daha küçük boyutlarda olma eğilimindeydi. Bu özellikleri malignleşme risklerinin düşük olması ile koreledir.

Ileri adenom hastalarımızın ortalama yaşlarının yüksek olması ve kolonun her yerinde çok sayıda polip olanlar arasında daha sık görülmesi; yaşın kolon kanseri gelişiminde bir risk faktörü olması ve aynı zamanda farklı lokalizasyonlarda çok sayıda polip varlığı ile uyumludur $(26,27)$.

Adenokarsinom, kolonoskopi yapilan tüm hastaların (17/827) \%2,05'inde saptandi. Hispanik'lerde (24) \%1,4'tü. Laird-Fick ve arkadaşlarının (25) 50 yaş üstü hastalarında $\% 0,2$, Odom ve arkadaşlarının (28) üç yıllık tek topluluk çalışmasında \%0,3 oranında, Avusturya'da prospektif dört yllık bir tarama çalışmasında \%1,1 iken Ulusal Polip Çalışması kayıt evresinde \%6'ya kadar daha yüksek oranlar bulmuştur. Adenom-karsinom dönüşüm teorisine $(11,12)$ uygun olarak bölgemizde polip sıklığının Batı ülkeleri ve Tayvan'da yapılan çalışmalarda bulunan oranlardan daha yüksek olması karsinom sıklığını da arttırmaktadır. Adenokarsinomların büyük çoğunluğu $(\% 88,2)$ rektosigmoid lokalizasyonda olması, izlemlerin rektosigmoidoskopi ile yapılabileceğini göstermektedir.

Sonuç olarak, adenomatöz poliplerde pankolonik tutulum, poliplerin daha büyük, özellikle 10 mm'den büyük olması, polip sayısının 10'un üzerinde olması hiperplastik poliplere göre daha sık görülmektedir. Erkek cinsiyet, ileri yaş ve polip sayısı artışı ileri adenom ve adenokarsinom gelişme riskini artmaktadır. Bu grup hastaların yakın takip ve izlem programlarına alınması uygun olacaktır. Bununla birlikte daha geniş kapsamlı izlem çalışmalarına ihtiyaç vardır.

\section{KAYNAKLAR}

1. Arnold M, Sierra MS, Laversanne M, et al. Global patterns and trends in colorectal cancer incidence and mortality. Gut Epub 2016 Jan 27.

2. Ferlay J, Shin HR, Bray F, et al. Estimates of worldwide burden of cancer in 2008: GLOBOCAN 2008. Int J Cancer 2010;127:2893-917.

3. Winawer SJ, Sherlock P. Colorectal cancer screening. Best Prac Res Clin Gastroenterol 2007;21:1031-48.

4. Eddy DM. Screening for colorectal cancer. Ann Intern Med 1990;113:373-84.

5. Parkin DM, Pisani, P, Ferlay, J. Global cancer statistics. CA Cancer J Clin 1999;49:33-64

6. Ashktorab H, Nouraie M, Hosseinkhah F, et al. A 50-year review of colorectal cancer in African Americans: implications for prevention and treatment. Dig Dis Sci 2009;54:1985-90.

7. Sung JJ, Ng SC, Chan FK, et al; Asia Pacific Working Group. An updated Asia Pacific Consensus Recommendations on colorectal cancer screening. Gut 2015;64:121-32.

8. Cherian T, Mahadevan P, Chandramathi S, et al. Increasing cancer incidence in a tertiary care hospital in a developing country, India. Indian J Cancer 2015;52:133-8

9. Trimbath JD, Giardiello FM. Review article: Genetic testing and counselling for hereditary colorectal cancers. Aliment Pharmacol Ther 2002;16:1843-57.

10. Winawer SJ, Zauber AG, Ho MN, et al. Prevention of colorectal cancer by colonoscopic polypectomy. The National Polyp Study Workgroup. N Engl J Med 1993;329:1977-81.

11. Risio M. The natural history of adenomas. Best Pract Res Clin Gastroenterol 2010;24:271-80.

12. Paik JH, Jung EJ, Ryu CG, Hwang DY. Detection of polyps after resection of colorectal cancer. Ann Coloproctol 2015;31:182-6.

13. Brenner H, Hoffmeister M, Stegmaier C, et al. Risk of progression of advanced adenomas to colorectal cancer by age and sex: estimates based on 840.149 screening colonoscopies. Gut 2007;56:1585-9.

14. Atkin WS, Saunders BP, British Society for Gastroenterology; Association of Coloproctology for Great Britain and Ireland. Surveillance guidelines after removal of colorectal adenomatous polyps. Gut 2002;51:V6-9.

15. Atkin WS, Morson BC, Cuzick J. Long-term risk of colorectal cancer after excision of rectosigmoid adenomas. N Engl J Med 1992;326:65862. 
16. Winawer SJ, Zauber AG, Gerdes H, et al. Risk of colorectal cancer in the families of patients with adenomatous polyps. National Polyp Study Workgroup. N Engl J Med 1996;334:82-7.

17. Strum WB. Colorectal adenomas. N Engl J Med 2016;374:1065-75.

18. Fairley KJ, Li J, Komar M, et al. Predicting the risk of recurrent adenoma and incident colorectal cancer based on findings of the baseline colonoscopy. Clin Transl Gastroenterol 2014;5:e64.

19. Müller AD, Sonnenberg A. Prevention of colorectal cancer by flexible endoscopy and polypectomy. A case-control study of 32.702 veterans. Ann Intern Med 1995;123:904-10.

20. Burt RW, DiSario JA, Cannon-Albright L. Genetics of colon cancer: impact of inheritance on colon cancer risk. Annu Rev Med 1995; 46:371-9.

21. Ashktorab H, Laiyemo AO, Lee E, et al. Prevalence and features of colorectal lesions among Hispanics: A hospital-based study. World J Gastroenterol 2015;21:13095-100

22. Corley DA, Jensen CD, Marks AR, et al. Variation of adenoma prevalence by age, sex, race, and colon location in a large population: implications for screening and quality programs. Clin Gastroenterol Hepatol 2013;11:172-80
23. Wang FW, Hsu PI, Chuang HY, et al. Prevalence and risk factors of asymptomatic colorectal polyps in Taiwan. Gastroenterol Res Pract. 2014;2014:985205.

24. Laird-Fick HS, Chahal G, Olomu A, et al. Colonic polyp histopathology and location in a community-based sample of older adults. BMC Gastroenterol 2016;16:90.

25. Siegel R, Naishadham D, Jemal A. Cancer statistics, 2013. CA Cancer J Clin 2013;63:11-30.

26. Nguyen SP, Bent S, Chen YH, Terdiman JP. Gender as a risk factor for advanced neoplasia and colorectal cancer: a systematic review and meta-analysis. Clin Gastroenterol Hepatol 2009;7:676-81.el-3.

27. Odom SR, Duffy SD, Barone JE, et al. The rate of adenocarcinoma in endoscopically removed colorectal polyps. Am Surg. 2005;71:1024-6.

28. Winawer SJ, Zauber AG, O'Brien MJ, et al. The National Polyp Study. Design, methods, and characteristics of patients with newly diagnosed polyps. The National Polyp Study Workgroup. Cancer 1992;70(5 Suppl):1236-45. 